\title{
The six-minute stepper test is related to muscle strength but cannot substitute for the one repetition maximum to prescribe strength training in patients with COPD
}

This article was published in the following Dove Medical Press journal:

International Journal of COPD

Tristan Bonnevie, ${ }^{1,2}$ Mathilde

Allingham, ${ }^{3}$ Guillaume

Prieur, ${ }^{1,4}$ Yann Combret, ${ }^{5,6}$

David Debeaumont, ${ }^{7}$ Maxime

Patout, ${ }^{1,8}$ Antoine Cuvelier, ${ }^{1,8}$

Catherine Viacroze, ${ }^{8}$ Jean-

François Muir, ${ }^{1,2,8}$ Clement

Medrinal, ${ }^{1,4}$ Francis-Edouard

Gravier ${ }^{1,2}$

'Normandie University, UNIROUEN, UPRES EA 3830, Rouen University Hospital, Haute Normandie Research and Biomedical Innovation, Rouen, France; ${ }^{2}$ ADIR Association, Rouen University Hospital, Rouen, France; ${ }^{3}$ Rouen University Hospital, School of Physiotherapy, Rouen, France; ${ }^{4}$ Intensive Care Unit Department, Le Havre Hospital, Hôpital Jacques

Monod, Montivilliers, France; 5 Institute of Experimental and Clinical Research (IREC), Pole of Pulmonology, ORL and Dermatology, Catholic University of Louvain, Brussels, Belgium; ${ }^{6}$ Physiotherapy Department, Le Havre Hospital, Le Havre, France; ' ${ }^{7}$ Department of Respiratory and Exercise Physiology and CIC-CRB I404,

Rouen University Hospital, Rouen, France; ${ }^{8}$ Pulmonary, Thoracic Oncology and Respiratory Intensive Care Department, Rouen University Hospital, Rouen, France

Correspondence: Tristan Bonnevie ADIR Association, Rouen University Hospital, Rouen, France

Tel +33235592970

Fax +3323559297।

Email rehabilitation@adir-hautenormandie.com
Purpose: There are many barriers to pulmonary rehabilitation, including a limited access to evaluation centers. To cope with these difficulties, field tests are often used to prescribe endurance training. As field tests are related to muscle strength, they could also be used to prescribe strength training and increase the access to pulmonary rehabilitation in rural area. However, their validity for this purpose has never been studied.

Patients and methods: The relationship between the 6-minute stepper test (6MST), 6-minute walk test, maximal workload achieved during cardiopulmonary exercise testing (Wpeak), and one repetition maximum (1RM) was assessed in 35 patients with COPD through a retrospective chart review to derive predictive equation of the 1RM from these tests. The effectiveness of these equations to prescribe strength training at $70 \%$ of the $1 \mathrm{RM}$ was assessed in an independent cross-validation group of 34 patients with COPD.

Results: There was a moderate relationship between the 6MST, Wpeak and the 1RM $(r=0.44$ and $r=0.41$, respectively, both $P \leq 0.01$ ). Whatever the test, the prescription of strength training using the estimated 1RM compared with the measured 1RM resulted in a mean absolute difference and a mean bias of about $30 \mathrm{~kg}$.

Conclusion: The use of the 6MST and Wpeak for the prescription of strength training would result in a clinically not acceptable error. Therefore, they should not be used as a substitute for the $1 \mathrm{RM}$ to prescribe strength training.

Keywords: six-minute stepper test, strength training, COPD, pulmonary rehabilitation

\section{Introduction}

COPD is a worldwide cause of morbidity and mortality with a gradually increasing prevalence. ${ }^{1,2}$ Pulmonary rehabilitation is widely recommended to cope with the systemic effects of COPD ${ }^{3-5}$ and effectively improves exercise capacity and quality of life. ${ }^{6}$ Unfortunately, $<1 \%$ of patients who would benefit from it can access these programs, mainly due to the lack of rehabilitation and assessment centers, and their location in urban area. Pulmonary rehabilitation usually includes both endurance and strength training. ${ }^{3-5}$ Thus, although the optimal assessment for endurance training prescription should include cardiopulmonary exercise testing (CPET), ${ }^{3}$ it is often not available for a large number of patients. Alternatively, the one-repetition maximum (1RMw, which is the weight that can be lifted, pushed, or pulled only once without compensation) is 
frequently used in clinical practice for assessing and prescribing muscle strength. ${ }^{4,-11}$ However, it requires trained personnel and a learning period before the measurement to increase reliability and reduce bias, and is therefore time consuming. Moreover, it is possibly traumatic in several pathologies with comorbidities such as COPD (eg, bone, ligament, and muscular stress or injury). ${ }^{10}$ Therefore, it can be difficult to obtain due to pain or muscle fatigue even though sub-maximal strength training (about $70 \%$ of $1 \mathrm{RM}$ as usually prescribed) (12-15 will $^{4,15}$ be possible, highlighting a need for an easier and faster tool to assess and prescribe strength training.

Field tests have been proposed to replace CPET for the prescription of endurance training. ${ }^{16-21}$ For example, the 6-minute stepper test (6MST), which is easier to perform than the widely used 6-minute walk test (6MWT) and does not need a $30 \mathrm{~m}$ long corridor, ${ }^{22}$ has been validated to assess exercise capacity in patients with $\mathrm{COPD}^{23-25}$ and has recently been considered for endurance training prescription. ${ }^{17,20,21}$ Although field tests are often related to quadriceps muscular strength, ${ }^{26-28}$ their use for strength training prescription has not been studied.

The aim of this study was to assess whether the 6MST could be used to prescribe strength training in patients with COPD accurately. The usability of the maximal workload attained during the CPET (Wpeak) and the 6MWT was also studied.

\section{Materials and methods}

\section{Study design and patient selection}

Patients with COPD referred for pulmonary rehabilitation between September 2015 and October 2018 to the ADIR Association (Association d'aide à domicile des patients insuffisants respiratoires), Rouen University Hospital, France, were retrospectively studied. The study was approved by the Comite d'Ethique de la Recherche non-interventionnelle from Rouen University Hospital (E2018-67). According to the French law, patients were informed in writing that their data could be used for future research purposes and formal consent to retrospectively review their medical records was not required. None of these patients used this right of refusal. Patient data confidentiality was maintained and the protocol was performed in compliance with the Declaration of Helsinki.

\section{Inclusion criteria}

Patients with a clinical diagnosis of COPD $\left(\mathrm{FEV}_{1} / \mathrm{FVC}\right.$ ratio $<0.70$ ) were included. The severity of airflow limitation was assessed according to the GOLD classification. ${ }^{29}$ They had to be 18 years old; stable (free from acute exacerbation in the previous month); and have performed both the 6MST and the quadriceps 1RM assessment during the first session of their pulmonary rehabilitation. They also had to weigh $90 \mathrm{~kg}$ or less (maximum weight supported by the stepper).

\section{Exclusion criteria}

Patients for whom the quadriceps 1RM exceeded $120 \mathrm{~kg}$ on one limb (leg press's limit) and those for whom the $1 \mathrm{RM}$ was not maximal due to musculoskeletal limitation were excluded.

\section{Data extraction}

Data regarding demographic features, comorbidities, pulmonary function, exercise capacity (6MST, Wpeak, and $6 \mathrm{MWT}$ ), quadriceps 1RM, and use of long-term oxygen or home mechanical ventilation were extracted though a retrospective chart review.

\section{Assessment}

\section{IRM}

Quadriceps 1RM was performed on a pulley press (Legpress; Design Corporel, Salomé, France). Patients were in a semi-sitting position, back against the backside with a $90^{\circ}$ knee and hip flexion. ${ }^{30}$ They were vigorously encouraged to extend both of their knees simultaneously. Patients had to put their hands on the side handles of the press or to keep them on their stomach. In the case of values exceeding $120 \mathrm{~kg}$ divided over the two lower limbs, the press reached its limit. Therefore, the search for the 1RM value proceeded as before: with a progressive rise in the weight if the lift was successful, however it was now realized on the one leg. Therefore, patients were told to put the foot of the exercising lower limb in the middle of the steel plate and the other lower limb (not exercising) on the sliding rail in order to avoid any compensation. The sum of both lower limbs was considered as quadriceps 1RM.

\section{MST}

Patients performed two 6MSTs (Athlitec; GoSport, Sassenage, France). The second test began when the heart rate $(\mathrm{HR})$, and the transcutaneous oxygen saturation $\left(\mathrm{SpO}_{2}\right)$ values returned to baseline values after a rest period of at least 20 minutes. The performance of the second test was recorded for analysis. ${ }^{20}$ Standardized instructions were based on the American Thoracic Society guidelines for the 6MST as previously described. ${ }^{23}$

\section{CPET}

CPET was performed on an electromagnetic braked ergometer (Ergoselect 200; Ergoline, Bitz, Germany). 
Following a 3 minutes warm-up period, incremental ramp exercise (5-20 W/min) was applied up to exhaustion. A pneumotachograph and a gas analyzer (Ergocard; Medisoft, Louvain, Belgium) were used to measure gases (oxygen consumption $\left[\mathrm{VO}_{2}\right]$ and carbon dioxide production $\left[\mathrm{VCO}_{2}\right]$ breath by breath) through a face mask (Hans Rudolph, Inc., Kansas City, MO, USA). The last ramp maintained before exhaustion or the workload achieved at $\mathrm{VO}_{2}$ peak was considered as Wpeak.

\section{MWT}

The 6MWT was performed according to the American Thoracic Society guidelines along a $30 \mathrm{~m}$ corridor. ${ }^{22}$ The test was carried out twice and the longest distance was used in the analysis.

\section{Outcome}

The evaluation of the reliability of using the 6MST to prescribe the strength training involved four steps. First, the relation between the number of steps performed during the 6MST and the quadriceps 1RM was assessed in the first group of subjects (prediction group) with COPD.${ }^{31}$ Next, in the case of a significant relationship, a linear regression was performed to derive a predictive equation of the $1 \mathrm{RM}$ from the $6 \mathrm{MST}$. Third, in a second and independent cross-validation group of subjects with COPD, the quadriceps 1RM was estimated from the predictive equation. The last step was to assess the error that would be associated with using estimated 1RM to prescribe strength training in a clinical situation ( $70 \%$ of the $1 \mathrm{RM}){ }^{4,12-15}$ The same method was applied for both Wpeak and the 6MST.

\section{Statistical analysis}

The normality of the distribution was assessed using the Kolmogorov-Smirnov test. Categorical data were expressed as counts (\%) and continuous data were expressed as mean (SD) or median (25th-75th percentile) according to the distribution. Comparison between the baseline characteristics of both groups was assessed with Fisher's test (for proportion) and independent Student's $t$-test or Mann-Whitney test, depending on the distribution.

\section{Determination of the predictive equation in the prediction group}

The relationship between the 6MST, Wpeak, 6MWT, and 1RM was assessed using Pearson or Spearman correlation test. Single linear regressions were performed when appropriate. Since several data were not normally distributed, they were normalized using a log-transformation. A predictive equation using linear regression was then derived.

\section{Validation of the predictive equation in cross- validation group}

The comparison of the prescribed workload (70\% 1RM) between the measured 1RM and the estimated 1RM was assessed using the mean absolute difference (MAD) between both prescription and a Bland-Altman analysis. As the increment of the leg press is done by $5 \mathrm{~kg}$, the prescriptions were a priori considered as clinically equivalent if the limits of agreements (upper and lower bounds) were $<5 \mathrm{~kg}$. A $P$-value $<0.05$ was deemed significant. Prism 5 software was used for analyses.

\section{Results Patients}

Among the 356 patients referred for pulmonary rehabilitation over the study period, 78 met the inclusion criteria. Two were excluded because the quadriceps 1RM exceeded 120 $\mathrm{kg}$ on one limb. A further seven were excluded from the analysis because the 1RM was limited due to musculoskeletal impairment (Figure 1). Finally, 69 patients were included for the analysis. The first 35 patients were selected to derive the predictive equations, ${ }^{31}$ while the 34 subsequent patients were used to assess the validity of the equations to prescribe strength training (cross-validation group). The patients' characteristics of both groups are shown in Table 1. Overall, the mean age was 60 (SD 10) years, 42\% were women, and $30 \%$ were long-term oxygen users. They had a severe obstruction (median $\mathrm{FEV}_{1} \%$ : 38 [IQR 30-58]) and impaired

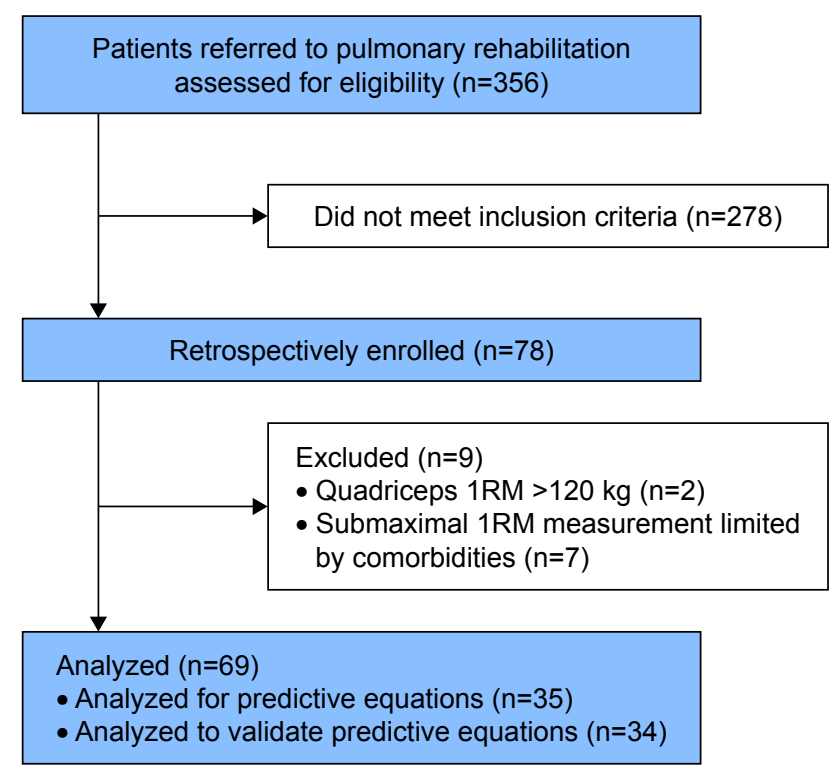

Figure I Flow of patients through the study.

Abbreviation: IRM, one repetition maximum test. 
Table I Characteristics of the patients

\begin{tabular}{|c|c|c|c|}
\hline \multirow[t]{2}{*}{ Characteristics } & \multicolumn{2}{|l|}{ Patients } & \multirow{2}{*}{$\begin{array}{l}\text { Between-group } \\
\text { comparison } \\
P \text {-value }\end{array}$} \\
\hline & $\begin{array}{l}\text { Prediction group } \\
(n=35)\end{array}$ & $\begin{array}{l}\text { Cross-validation group } \\
(n=34)\end{array}$ & \\
\hline Gender, $\mathrm{n}$ female (\%) & $10(29)$ & $19(56)$ & 0.03 \\
\hline Age (years), mean (SD) & $61(9)$ & $59(11)$ & 0.40 \\
\hline Height $(\mathrm{cm})$, mean (SD) & $167(8)$ & $165(9)$ & 0.40 \\
\hline Body mass (kg), mean (SD) & $61(14)$ & $64(15)$ & 0.54 \\
\hline Body mass index $\left(\mathrm{kg} / \mathrm{m}^{2}\right)$, mean $(\mathrm{SD})$ & $21.9(4.1)$ & $23.2(4.7)$ & 0.22 \\
\hline $\mathrm{FEV}_{1}(\mathrm{~L})$, median (IQR) & $1.0(0.7-1.6)$ & I.I (0.8-I.7) & 0.54 \\
\hline $\mathrm{FEV}_{1}(\%)$, median (IQR) & $36(26-58)$ & $43(32-59)$ & 0.30 \\
\hline FVC (L), median (IQR) & $2.6(2.0-3.4)$ & $2.5(1.8-3.4)$ & 0.63 \\
\hline $\mathrm{FEV}_{\mathrm{I}} / \mathrm{FVC}(\%)$, mean (SD) & $43(12)$ & $48(13)$ & 0.15 \\
\hline Residual volume to total lung capacity, mean (SD) & $0.6(0.1)$ & $0.6(0.1)$ & 0.18 \\
\hline $\mathrm{VO}_{2}$ peak (mL/kg/min), mean (SD) & $14(3)$ & $14(4)$ & 0.40 \\
\hline Wpeak (W), median (IQR) & $70(40-80)$ & $50(40-80)$ & 0.72 \\
\hline 6MST (steps), mean (SD) & $195(62)$ & $190(70)$ & 0.74 \\
\hline 6MWT distance $(\mathrm{m})$, median (IQR) & $451(416-490)$ & $420(38 I-510)$ & 0.64 \\
\hline Quadriceps IRM (kg), median (IQR) & $100(90-140)$ & $100(84-153)$ & 0.58 \\
\hline Long-term oxygen use, n (\%) & $13(37)$ & $8(24)$ & 0.30 \\
\hline Home mechanical ventilation use, $n(\%)$ & $6(17)$ & $5(15)$ & 1.00 \\
\hline \multicolumn{4}{|l|}{ Comorbidities, n (\%) } \\
\hline Peripheral arterial disease, $\mathrm{n}(\%)$ & $4(\mathrm{II})$ & $0(0)$ & 0.11 \\
\hline Hypertension, n (\%) & $8(23)$ & $3(9)$ & 0.19 \\
\hline Hypercholesterolemia, n (\%) & $7(20)$ & I (3) & 0.06 \\
\hline Diabetes, n (\%) & $3(9)$ & I (3) & 0.61 \\
\hline Cardiopathies, n (\%) & $4(\mathrm{II})$ & $5(15)$ & 0.73 \\
\hline Lung cancer, n (\%) & $7(20)$ & $6(18)$ & 1.00 \\
\hline
\end{tabular}

Notes: Percentages may not sum to 100 due to rounding. Fisher's test for categorial data, and Mann-Whitney or independent $t$-test for other characteristics. Bold values indicate statistical significance.

Abbreviations: $\mathrm{VO}_{2}$ peak, maximal oxygen consumption; 6MST, 6-minute stepper test; 6MWT, 6-minute walk test; IRM, one repetition maximum test; Wpeak, maximal workload achieved during cardiopulmonary exercise testing.

exercise capacity (mean $\mathrm{VO}_{2}$ peak: 14 [SD 4$] \mathrm{mL} / \mathrm{kg} / \mathrm{min}$ ). There were significantly more females in the cross-validation group (56\% compared with $29 \%, P=0.03$ ).

\section{Relationship with the IRM (prediction group)}

There was a significant relationship between the $6 \mathrm{MST}$, Wpeak and $\log 1 \mathrm{RM}(r=0.44, P<0.01$ and $r=0.41, P=0.01$, respectively, Figure $2 \mathrm{~A}$ and $\mathrm{B})$. The $6 \mathrm{MWT}$ was only available for 13 patients and there was no significant relationship with $\log 1 \mathrm{RM}$.

\section{Predictive equations (prediction group)}

Log1RM could be predicted, respectively, for the $6 \mathrm{MST}$ and Wpeak by the following equations (Figure $2 \mathrm{~A}$ and $\mathrm{B}$ ):

$$
\begin{gathered}
\log 1 \mathrm{RM}=0.0009379 \times 6 \mathrm{MST}(\text { steps })+1.713 \\
\log 1 \mathrm{RM}=0.00223 \times \operatorname{Wpeak}(\mathrm{W})+1.757
\end{gathered}
$$

As the 6MWT was not correlated with $\log 1 \mathrm{RM}$, no predictive equation was derived.

\section{Validation of the predictive equations (cross-validation group)}

The MAD between the prescriptions of strength training at a value of $70 \%$ of the $1 \mathrm{RM}$ using the actually measured and the predicted 1RM was 31 (SD 30) $\mathrm{kg}$ for the 6MST and 29 (SD 28) kg for Wpeak. The limits of agreement and corresponding Bland-Altman plots are presented for the 6MST in Figure 3A and for Wpeak in Figure 3B.

\section{Discussion}

The main finding of this study was that there was a significant relationship between exercise capacity assessment tests used to prescribe endurance training and the 1RM. However, this relationship was only moderate, and the use 

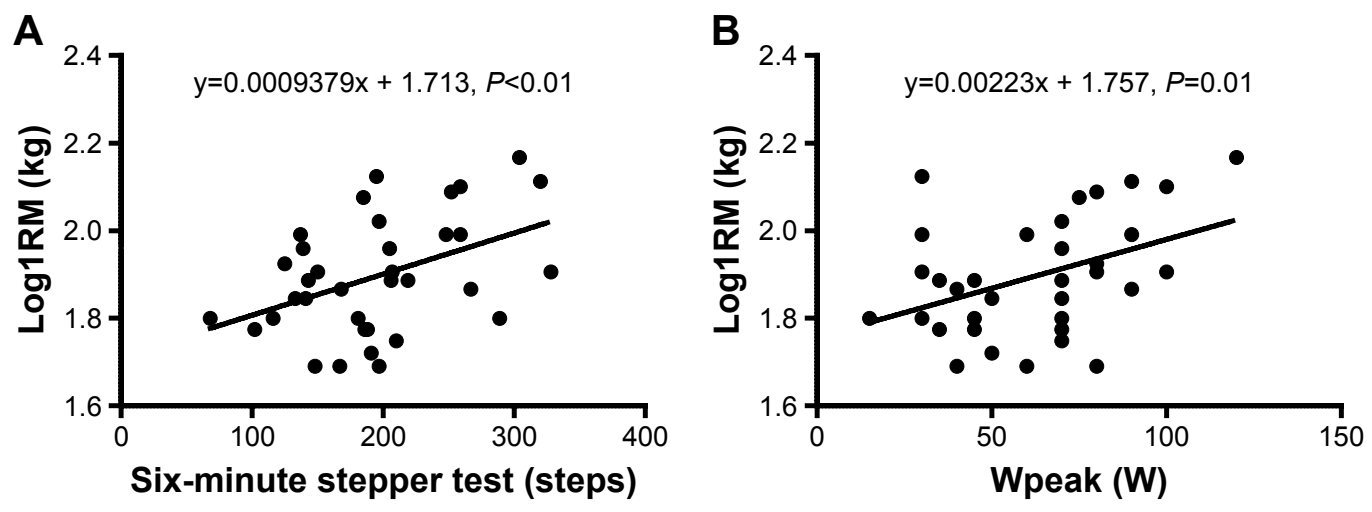

Figure 2 Linear relationship and predictive equations between $(\mathbf{A})$ the 6-minute stepper test, $(\mathbf{B})$ the maximal workload achieved during the cardiopulmonary exercise testing (Wpeak) and the one repetition maximum (IRM).

of predictive equations to estimate the $1 \mathrm{RM}$ from these tests to prescribe strength training would result in an inacceptable error for clinical practice (about $30 \mathrm{~kg}$ ). As can be seen in Figure $3 \mathrm{~A}$ and $\mathrm{B}$, the amount of error seems to increase with the increase of the $1 \mathrm{RM}$.

The assessment of the 1RM is the gold standard for strength training prescription. ${ }^{4,9}$ However, it could be compromised in pathological condition and is time consuming. ${ }^{11}$ Although the measurement of the 1RM was found to be feasible in a small cohort of patients with COPD, ${ }^{30}$ it might be limited by comorbidities. In the present study, about $10 \%$ of the patients were excluded due to pain (due to musculoskeletal comorbidities) during the measurement, which led to an underestimation of the 1RM even though strength training at $70 \% 1 \mathrm{RM}$ would have been possible. Therefore, indirect measurement of the 1RM to allow effective training seems necessary.

There are many barriers to pulmonary rehabilitation, including a limited access to evaluation centers and CPET. ${ }^{7,8}$ To cope with these difficulties, field tests are often used to prescribe endurance training. ${ }^{16-21}$ As several field tests are related to muscle strength, ${ }^{26,27}$ as well as the 6MST in the present study, the idea to use the same test to prescribe both endurance and strength training looks attractive at the first glance to increase the access to pulmonary rehabilitation in rural area. Surprisingly, there was no relationship between the $6 \mathrm{MWT}$ and the 1RM. Conversely, Rausch-Osthoff et al found a significant moderate correlation between the quadriceps strength and the distance covered during 6MWT. ${ }^{27}$ This difference was likely due to the few numbers of 6MWT records available in subjects from the prediction group because the study was not designed for this outcome.

However, the present results suggest that the use of both the 6MST and CPET to prescribe strength training would result in a significant error, refuting their use for clinical practice. In healthy subjects, several authors suggested the use of anthropologic data such as age, gender, height, weight, lean body mass, and thigh girth. ${ }^{10}$ Adding these characteristics in a multivariate analysis in a larger cohort of subjects with COPD may help to refine the present equations and improve their
A

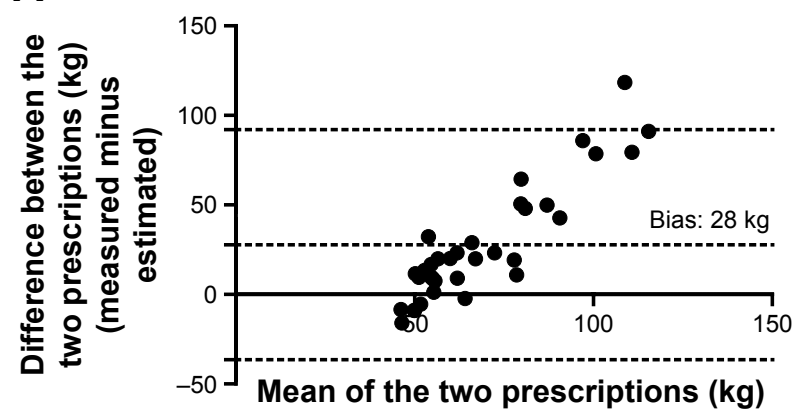

B

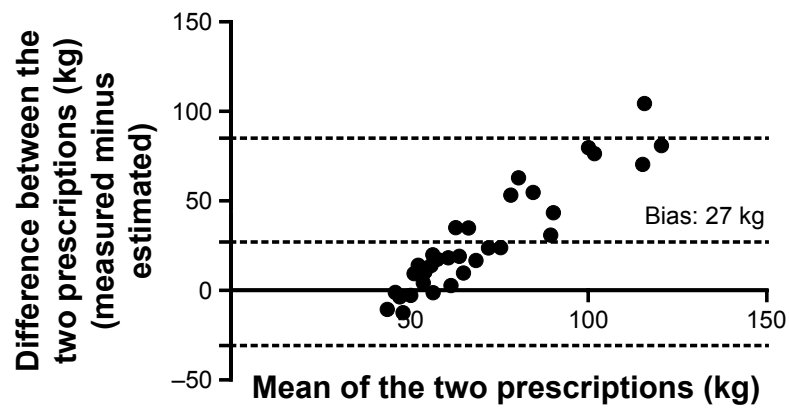

Figure 3 Bland-Altman plots for the prescription of strength training using the predictive equations derived from the 6-minute stepper test (A) and Wpeak (B). The pointto-point difference between the two prescriptions (actually measured minus estimated) is plotted against the mean of the two prescriptions. $95 \% \mathrm{Cl}$ limits of agreement (lower and upper bounds) were -36 to 92 for the 6MST and -31 to 85 for Wpeak.

Abbreviations: 6MST, 6-minute stepper test; Wpeak, the maximal workload achieved during the cardiopulmonary exercise testing. 
accuracy to prescribe strength training. Alternatively, the prediction of the 1RM from the perceived exertion (BORG scale $)^{11,32}$ has been proposed for healthy subjects but remains to be evaluated in subjects with COPD.

There are several explanations for the inaccuracy that occurred when using the estimated 1RM to prescribe strength training.

First, the relationship between Wpeak, 6MST and the 1 RM was only moderate $(r=0.40)$. Since cycling, stepping, and strength training provide substantially different effort and metabolic load, ${ }^{33-36}$ several parameters such as ventilatory pattern, hematosis, cardiovascular adaptation, muscle mass involved, weight, and balance may explain this moderate correlation. Moreover, compared with endurance capacity, muscular strength is relatively well preserved in patients with COPD due to a shift toward an increased proportion of fast twitch muscular fiber (type II), which are specifically recruited during strength training and the 1RM assessment. ${ }^{37}$ Conversely, Wpeak and the 6MST do not only reflect the type II fibers activity but also include the recruitment of the slow twitch fibers (type I), as suggested by the relationship between the 6MST and $\mathrm{VO}_{2}$ peak. ${ }^{25}$ This may also contribute to explain the systematic bias observed in the Bland and Altman analysis (Figure 3) showing that the error increases proportionally to the 1RM (eg, the least disabled patients had a preserved type II fibers and a high 1RM but likely an already present alteration of the type I fibers and therefore a relatively low performance on the 6MST). Additionally, the nature of the 1RM assessment and strength training allows the patients to rest between repetitions while the exercise is continuous during cycling or stepping, causing more dyspnea and fatigue in the latter. ${ }^{36}$ This likely allowed a more important recruitment of muscular fibers during the assessment of the 1RM.

Secondly, there were significantly more females in the cross-validation group. This might have introduced some bias due to gender, since it has an impact on perceived dyspnea ${ }^{38}$ and muscular type fibers. ${ }^{39}$ However, the latter is reported inconsistently, ${ }^{40}$ and there are no gender differences in cardiopulmonary responses during the $1 \mathrm{RM}$ testing. ${ }^{30}$ Therefore, it is unlikely that these factors alone account for the amount of error observed between both prescriptions.

\section{Limits and strength}

First, a bias cannot be excluded due to the retrospective design of the study. However, this reflected daily clinical practice providing external validity of the results. Moreover, statistical tests were limited to those reported in order to avoid any type one error due to multiple comparison frequently encountered in retrospective studies. Secondly, the population was relatively selected (eg, no major balance impairment and weight under $90 \mathrm{~kg}$ for the 6MST). This cannot be neglected considering that a considerable number of patients with COPD are overweight ${ }^{41,42}$ and present balance disorders. ${ }^{43}$

The most important strength of this study was the evaluation of the predictive equation in an independent crossvalidation group which has invalidated the use of both tests for the prescription of strength training.

\section{Conclusion}

Wpeak and the 6MST are both related to the quadriceps strength (1RM). Although the CPET and the 6MST could be used to prescribe endurance training in patients with COPD, their use for the prescription of strength training would result in a clinically nonacceptable error. Therefore, they should not be used for this purpose and both the 1RM and the voluntary maximal contraction remain the recommended methods to assess muscle strength in clinical practice. Further prospective studies are needed to confirm these results and explore the potential usefulness of the 6MWT for this purpose.

\section{Ethics approval}

This study was approved by the Comité d'Ethique de la Recherche non-interventionnelle from Rouen University Hospital (E2018-67).

\section{Data sharing statement}

Deidentified participant data published in the manuscript will be shared to searchers performing a meta-analysis on request. Data will be available after publication.

\section{Acknowledgments}

We thank ADIR Assistance, Asten group, Gwenaëlle Leteurtre for support during data collection, and Johanna Robertson for revision of the English text. This work was supported by ADIR Association.

\section{Disclosure}

Dr MP reports grants from B\&D Electromedical, personal fees from ResMed and Philips Respironics, grants and nonfinancial support from Fisher \& Paykel, nonfinancial support from MSD, nonfinancial support from Asten, and grants from ADIR Association, outside the submitted work. The other authors report no conflicts of interest in this work. 


\section{References}

1. Lozano R, Naghavi M, Foreman K, et al. Global and regional mortality from 235 causes of death for 20 age groups in 1990 and 2010 : a systematic analysis for the global burden of Disease Study 2010. The Lancet. 2012;380(9859):2095-2128.

2. Khakban A, Sin DD, Fitzgerald JM, et al. The projected epidemic of chronic obstructive pulmonary disease hospitalizations over the next 15 years. A population-based perspective. Am J Respir Crit Care Med. 2017;195(3):287-291.

3. Société de Pneumologie de Langue Française. Recommandation pour la Pratique Clinique : prise en charge de la BPCO. Rev Mal Respir. 2010;27:522-548. French.

4. Spruit MA, Singh SJ, Garvey C, et al. An official American Thoracic Society/European Respiratory Society statement: key concepts and advances in pulmonary rehabilitation. Am J Respir Crit Care Med. 2013;188(8):e13-e64.

5. Bolton CE, Bevan-Smith EF, Blakey JD, et al. British Thoracic Society guideline on pulmonary rehabilitation in adults. Thorax. 2013; 68(Suppl 2):ii1-ii30.

6. Mccarthy B, Casey D, Devane D, et al. Pulmonary rehabilitation for chronic obstructive pulmonary disease. Cochrane Database Syst Rev. 2015;3(1):CD003793.

7. Brooks D, Sottana R, Bell B, et al. Characterization of pulmonary rehabilitation programs in Canada in 2005. Can Respir J. 2007;14(2): 87-92.

8. Stickland MK, Jourdain T, Wong EYL, Rodgers WM, Jendzjowsky NG, Macdonald GF. Using telehealth technology to deliver pulmonary rehabilitation to patients with chronic obstructive pulmonary disease. Can Respir J. 2011;18(4):216-220.

9. Levinger I, Goodman C, Hare DL, Jerums G, Toia D, Selig S. The reliability of the 1RM strength test for untrained middle-aged individuals. J Sci Med Sport. 2009;12(2):310-316.

10. Reynolds JM, Gordon TJ, Robergs RA. Prediction of one repetition maximum strength from multiple repetition maximum testing and anthropometry. J Strength Cond Res. 2006;20(3):584-592.

11. Eston R, Evans HJ. The validity of submaximal ratings of perceived exertion to predict one repetition maximum. J Sports Sci Med. 2009; 8(4):567-573.

12. Sillen MJ, Franssen FM, Delbressine JM, Vaes AW, Wouters EF, Spruit MA. Efficacy of lower-limb muscle training modalities in severely dyspnoeic individuals with COPD and quadriceps muscle weakness: results from the DICES trial. Thorax. 2014;69(6):525-531.

13. Zambom-Ferraresi F, Cebollero P, Gorostiaga EM, et al. Effects of combined resistance and endurance training versus resistance training alone on strength, exercise capacity, and quality of life in patients with COPD. J Cardiopulm Rehabil Prev. 2015;35(6):446-453.

14. Ortega F, Toral J, Cejudo P, et al. Comparison of effects of strength and endurance training in patients with chronic obstructive pulmonary disease. Am J Respir Crit Care Med. 2002;166(5):669-674.

15. Covey MK, Collins EG, Reynertson SI, Dilling DF. Resistance training as a preconditioning strategy for enhancing aerobic exercise training outcomes in COPD. Respir Med. 2014;108(8):1141-1152.

16. Bonnet $\mathrm{P}$, Poulain M, Palomba B, et al. Utilisation du test de marche de 6 minutes pour individualiser un réentrainement l'effort chez le bronchopneumopathe chronique obstructif (BPCO). [Using the 6-minute walk test to individualize re-training effort in Chronic Obstructive Pulmonary Disease (COPD)] Revue des maladies respiratoires. 2001;18:2S63-62S64. French.

17. Fabre C, Chéhère B, Bart F, Mucci P, Wallaert B, Grosbois JM. Relationships between heart rate target determined in different exercise testing in COPD patients to prescribed with individualized exercise training. Int J Chron Obstruct Pulmon Dis. 2017;12:1483-1489.

18. dal Corso S, de Camargo AA, Izbicki M, Malaguti C, Nery LE. A symptom-limited incremental step test determines maximum physiological responses in patients with chronic obstructive pulmonary disease. Respir Med. 2013;107(12):1993-1999.
19. Zainuldin R, Mackey MG, Alison JA. Prescription of walking exercise intensity from the 6-minute walk test in people with chronic obstructive pulmonary disease. J Cardiopulm Rehabil Prev. 2015;35(1): 65-69.

20. Bonnevie T, Gravier F-E, Leboullenger M, et al. Six-minute Stepper test to set pulmonary rehabilitation intensity in patients with COPD a retrospective study. COPD. 2017;14(3):293-297.

21. Bonnevie T, Gravier F-E, Cuvelier A, Debeaumont D. Six-Minute Stepper test to set pulmonary rehabilitation intensity in patients with COPD. COPD. 2018;15(1):91-92.

22. ATS Committee on Proficiency Standards for Clinical Pulmonary Function Laboratories. ATS statement: guidelines for the six-minute walk test. Am J Respir Crit Care Med. 2002;166(1):111-117.

23. Borel B, Fabre C, Saison S, Bart F, Grosbois JM. An original field evaluation test for chronic obstructive pulmonary disease population: the six-minute stepper test. Clin Rehabil. 2010;24(1):82-93.

24. Coquart JB, Lemaître F, Castres I, Saison S, Bart F, Grosbois J-M. Reproducibility and sensitivity of the 6-minute Stepper test in patients with COPD. COPD. 2015;12(5):533-538.

25. Grosbois JM, Riquier C, Chehere B, et al. Six-minute stepper test: a valid clinical exercise tolerance test for COPD patients. Int J Chron Obstruct Pulmon Dis. 2016;11:657-663.

26. Zanini A, Aiello M, Cherubino F, et al. The one repetition maximum test and the sit-to-stand test in the assessment of a specific pulmonary rehabilitation program on peripheral muscle strength in COPD patients. Int J Chron Obstruct Pulmon Dis. 2015;10:2423-2430.

27. Rausch-Osthoff AK, Kohler M, Sievi NA, Clarenbach CF, van Gestel AJ. Association between peripheral muscle strength, exercise performance, and physical activity in daily life in patients with chronic obstructive pulmonary disease. Multidiscip Respir Med. 2014; 9(1):37.

28. Gosselink R, Troosters T, Decramer M. Peripheral muscle weakness contributes to exercise limitation in COPD. Am J Respir Crit Care Med. 1996;153(3):976-980

29. Global Initiative for Chronic Obstructive Lung Disease. Global strategy for the diagnosis, management, and prevention of chronic obstructive pulmonary disease. 2018. Available from: https://goldcopd.org/goldreports/. Accessed March 22, 2019

30. Kaelin ME, Swank AM, Adams KJ, Barnard KL, Berning JM, Green A. Cardiopulmonary responses, muscle soreness, and injury during the one repetition maximum assessment in pulmonary rehabilitation patients. J Cardiopulm Rehabil. 1999;19(6):366-372.

31. Wilson van Voorhis CR, Morgan BL. Understanding power and rules of thumb for determining sample sizes. Tutor Quant Methods Psychol. 2007;3(2):43-50.

32. Borg GAV. Psychophysical bases of perceived exertion. Medicine, Science in Sports \& Exercise. 1982;14(5):377-381.

33. Mahler DA, Gifford AH, Waterman LA, Ward J, Machala S, Baird JC. Mechanism of greater oxygen desaturation during walking compared with cycling in patients with COPD. Chest. 2011;140(2):351-358.

34. Mathur RS, Revill SM, Vara DD, Walton R, Morgan MD. Comparison of peak oxygen consumption during cycle and treadmill exercise in severe chronic obstructive pulmonary disease. Thorax. 1995;50(8):829-833.

35. Singh SJ, Morgan MD, Hardman AE, Rowe C, Bardsley PA. Comparison of oxygen uptake during a conventional treadmill test and the shuttle walking test in chronic airflow limitation. Eur Respir J. 1994;7(11): 2016-2020.

36. Probst VS, Troosters T, Pitta F, Decramer M, Gosselink R. Cardiopulmonary stress during exercise training in patients with COPD Eur Respir J. 2006;27(6):1110-1118.

37. Couillard A, Prefaut C. From muscle disuse to myopathy in COPD potential contribution of oxidative stress. Eur Respir J. 2005;26(4): 703-719.

38. Guenette JA, Jensen D, Webb KA, Ofir D, Raghavan N, O'Donnell DE. Sex differences in exertional dyspnea in patients with mild COPD: physiological mechanisms. Respir Physiol Neurobiol. 2011;177(3): 218-227. 
39. Ausín P, Martínez-Llorens J, Sabaté-Bresco M, Casadevall C, Barreiro E, Gea J. Sex differences in function and structure of the quadriceps muscle in chronic obstructive pulmonary disease patients. Chron Respir Dis. 2017;14(2):127-139.

40. Torres SH, Montes de Oca M, Loeb E, Mata A, Hernández N. Gender and skeletal muscle characteristics in subjects with chronic obstructive pulmonary disease. Respir Med. 2011;105(1):88-94.

41. Eisner MD, Blanc PD, Sidney S, et al. Body composition and functional limitation in COPD. Respir Res. 2007;8(1):7.
42. Steuten LM, Creutzberg EC, Vrijhoef HJ, Wouters EF. COPD as a multicomponent disease: inventory of dyspnoea, underweight, obesity and fat free mass depletion in primary care. Prim Care Respir J. 2006; 15(2):84-91.

43. Porto EF, Castro AA, Schmidt VG, et al. Postural control in chronic obstructive pulmonary disease: a systematic review. Int $J$ Chron Obstruct Pulmon Dis. 2015;10:1233-1239.

\section{Publish your work in this journal}

The International Journal of COPD is an international, peer-reviewed journal of therapeutics and pharmacology focusing on concise rapid reporting of clinical studies and reviews in COPD. Special focus is given to the pathophysiological processes underlying the disease, intervention programs, patient focused education, and self management protocols.

\section{Dovepress}

This journal is indexed on PubMed Central, MedLine and CAS. The manuscript management system is completely online and includes a very quick and fair peer-review system, which is all easy to use. Visit http://www.dovepress.com/testimonials.php to read real quotes from published authors.

Submit your manuscript here: http://www.dovepress.com/international-journal-of-chronic-obstructive-pulmonary-disease-journal 